Corresponding authors: Pichurin. Pavel@mayo.edu; Klee.Eric@ mayo.edu

(c) 2017 Blackburn et al. This article is distributed under the terms of the Creative Commons Attribution-NonCommercial License, which permits reuse and redistribution, except for commercial purposes, provided that the original author and source are credited.

Ontology terms: bicornuate uterus; congenital strabismus; downturned corners of mouth; generalized neonatal hypotonia; hydronephrosis; hydroureter; low posterior hairline;

microretrognathia; moderate global developmental delay; neurogenic bladder; poor speech; recurrent urinary tract infections; short stature; urethral stricture; vesicoureteral reflux

Published by Cold Spring Harbor Laboratory Press

doi: $10.1101 /$ mcs.a001743

\section{Novel de novo variant in EBF3 is likely to impact DNA binding in a patient with a neurodevelopmental disorder and expanded phenotypes: patient report, in silico functional assessment, and review of published cases}

\author{
Patrick R. Blackburn, ${ }^{1,2,11}$ Sarah S. Barnett, ${ }^{3,11}$ Michael T. Zimmermann, ${ }^{4}$ \\ Margot A. Cousin, ${ }^{4,5}$ Charu Kaiwar, ${ }^{6,7}$ Filippo Pinto e Vairo, ${ }^{4,5}$ Zhiyv Niu, ${ }^{3,8}$ \\ Matthew J. Ferber, ${ }^{3,5,8}$ Raul A. Urrutia, ${ }^{9}$ Duygu Selcen, ${ }^{10}$ Eric W. Klee, ${ }^{3,4,5,8}$ \\ and Pavel N. Pichurin ${ }^{8}$

\begin{abstract}
${ }^{1}$ Center for Individualized Medicine, Mayo Clinic, Jacksonville, Florida 32224, USA; ${ }^{2}$ Department of Health Sciences Research, Mayo Clinic, Jacksonville, Florida 32224, USA; ${ }^{3}$ Department of Laboratory Medicine and Pathology, Mayo Clinic, Rochester, Minnesota 55905, USA; ${ }^{4}$ Department of Health Sciences Research, Mayo Clinic, Rochester, Minnesota 55905, USA; ${ }^{5}$ Center for Individualized Medicine, Mayo Clinic, Rochester, Minnesota 55905, USA; ${ }^{6}$ Department of Health Sciences Research, Mayo Clinic, Scottsdale, Arizona 85259, USA; ${ }^{7}$ Center for Individualized Medicine, Mayo Clinic, Scottsdale, Arizona 85259, USA; ${ }^{8}$ Department of Clinical Genomics, Mayo Clinic, Rochester, Minnesota 55905, USA; ${ }^{2}$ Laboratory of Epigenetics and Chromatin Dynamics, Epigenomics Translational Program, Center for Individualized Medicine, Mayo Clinic, Rochester, Minnesota 55905, USA; ${ }^{10}$ Department of Neurology, Mayo Clinic, Rochester, Minnesota 55905, USA
\end{abstract}

Abstract Pathogenic variants in EBF3 were recently described in three back-to-back publications in association with a novel neurodevelopmental disorder characterized by intellectual disability, speech delay, ataxia, and facial dysmorphisms. In this report, we describe an additional patient carrying a de novo missense variant in EBF3 (c.487C $>T$, p.(Arg163Trp)) that falls within a conserved residue in the zinc knuckle motif of the DNA binding domain. Without a solved structure of the DNA binding domain, we generated a homology-based atomic model and performed molecular dynamics simulations for EBF3, which predicted decreased DNA affinity for p.(Arg163Trp) compared with wild-type protein and control variants. These data are in agreement with previous experimental studies of EBF1 showing the paralogous residue is essential for DNA binding. The conservation and experimental evidence existing for EBF1 and in silico modeling and dynamics simulations to validate comparable behavior of multiple variants in EBF3 demonstrates strong support for the pathogenicity of p.(Arg163Trp). We show that our patient presents with phenotypes consistent with previously reported patients harboring EBF3 variants and expands the phenotypic spectrum of this newly identified disorder with the additional feature of a bicornuate uterus.

[Supplemental material is available for this article.]

\footnotetext{
${ }^{11}$ These authors contributed equally to this work.
} 


\section{INTRODUCTION}

The early B-cell factor 3 (EBF3) is a member of the Collier/Olf/EBF (COE) family of transcription factors that have a number of crucial developmental roles (Dubois and Vincent 2001). Recently, EBF3 was implicated in a novel neurodevelopmental disorder characterized by intellectual disability with or without central nervous system (CNS) malformations, speech delay, hypotonia, ataxia, facial dysmorphisms, and urogenital anomalies (Chao et al. 2016; Harms et al. 2016; Sleven et al. 2016). Three concurrent reports describing a total of 21 patients found several de novo heterozygous missense, nonsense, splice site, and small insertions and deletions involving EBF3 (Chao et al. 2016; Harms et al. 2016; Sleven et al. 2016). Interestingly, all of the missense variants that were identified fell within the highly conserved DNA binding domain (DBD) of EBF3; four had de novo missense variants within a single codon resulting in mutation of the p.Arg163 residue (Chao et al. 2016; Sleven et al. 2016). This residue falls within the "zinc knuckle" motif, is conserved across human EBF paralogs (EBF1-4), and has a crucial role in coordinating DNA binding (Hagman et al. 1995; Fields et al. 2008). Functional analysis of EBF1 p.Arg163Ala showed loss of DNA binding (Treiber et al. 2010). Functional studies of EBF3 variants affecting p.Arg163 have confirmed the essential role of this residue (Chao et al. 2016; Sleven et al. 2016). The EBF3 Arg163 codon falls within a CpG dinucleotide island, which could explain why it likely represents a mutation hotspot for this novel disorder (Chao et al. 2016). EBF3 binds to DNA as a homodimer but can also heterodimerize with other EBF family members to transactivate target genes (Green and Vetter 2011a). Studies of mutant/wild-type (wt) EBF3 heterodimers show that amino acid substitutions at critical residues could exert a dominant-negative effect, thereby reducing DNA binding and subsequent transcriptional activation (Sleven et al. 2016). In this report, we describe another patient with a novel heterozygous c.487C>T (p.(Arg163Trp)) variant in EBF3 who has significant clinical overlap with other previously described patients. We compare the clinical manifestations of our patient with those of previously reported individuals and also provide structural evidence supporting pathogenicity of the novel c.487C >T (p.(Arg163Trp)) variant found in this case.

\section{RESULTS}

\section{Clinical Presentation and Family History}

The proband was the product of an uncomplicated pregnancy, delivered at term to a G3P2, 31-yr-old mother and 34-yr-old father. She was noted at birth to have a markedly distended abdomen and was not voiding appropriately. A blind-end dimple was noted at the expected location of urethra and catheterization could not be performed. A percutaneous suprapubic cystoscopy was performed and vaginoscopy demonstrated a normal vagina and cervix with a bicornuate uterus. Urethral meatal stenosis was noted and the urethra was subsequently dilated. The suprapubic tube was removed but she had failed voiding trials, prompting vesicostomy and a diagnosis of atonic bladder. During her evaluation at $\sim 2 \mathrm{yr}$ of age, she had generalized hypotonia with global developmental delay; she sat independently at $1 \mathrm{yr}$, was not yet walking at $2 \mathrm{yr}$, and had a two- to three-word vocabulary. There was no evidence of ataxia or dystonia; deep tendon reflexes were reported decreased throughout. She had bilateral esotropia, short stature with height less than the second percentile, and weight and head circumference around the 25th percentile for age. On exam, she was grossly nondysmorphic, with downturned mouth corners, mild retrognathia, a low posterior hairline, and mild pectus excavatum (Fig. 1). She had normal evaluations that included brain and total spine magnetic resonance imaging (MRI), electromyography (EMG), chromosomal 

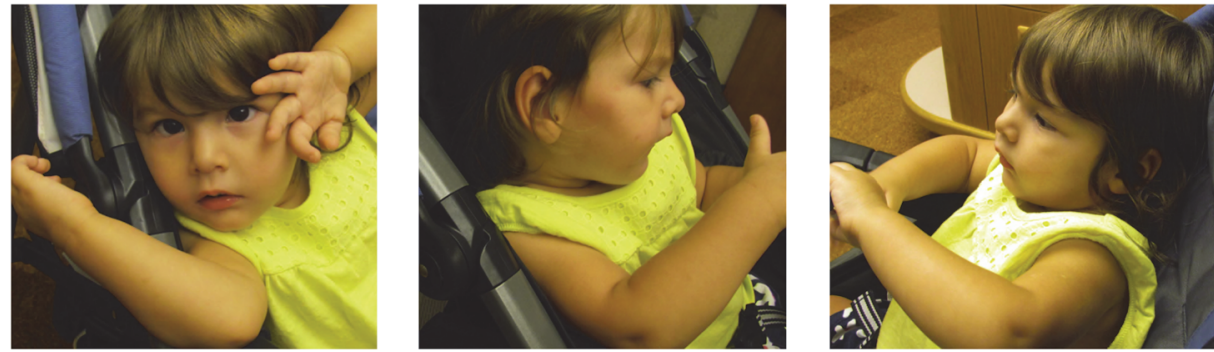

Figure 1. Patient photographs showing front and side views. The proband was noted to have mild dysmorphic features including bilateral esotropia, retrognathia, downturned corners of the mouth, and a low posterior hairline.

microarray, and comprehensive biochemical metabolic testing. There were no other family members with a similar constellation of findings; however, her mother and maternal grandmother were reported to have strabismus. The proband has two older maternal half-siblings including a sister with a history of attention-deficit/hyperactivity disorder (ADHD) and a brother with ADHD and history of speech delay.

\section{Genomic Analyses}

To identify variants of interest, whole-exome sequencing was performed on genomic DNA extracted from samples submitted from the proband, biological mother, and biological father; $97 \%$ of the exome-capture region was covered at a read depth of $20 \times$ or greater. A de novo variant (c.487C $>T$, p.(Arg163Trp)) was identified in EBF3, which was considered a gene of uncertain significance at the time of analysis (Table 1). This variant was reported due to EBF3 being implicated as part of the critical region in the $10 q 26$ microdeletion syndrome, which has features overlapping the clinical phenotype of the proband (Faria et al. 2016). In silico analyses predicted that this alteration was deleterious, probably damaging, and disease-causing by SIFT (Sorting Intolerant from Tolerant), PolyPhen-2, and MutationTaster2, respectively (Kumar et al. 2009; Adzhubei et al. 2010; Schwarz et al. 2014). This variant has not been reported in the literature or in publically available databases including the Exome Aggregation Consortium (ExAC) and the Genome Aggregation Database (gnomAD) (Lek et al. 2016). EBF3 is highly intolerant to both missense and lossof-function variation, and the residue mutated in our patient is conserved across species and paralogs (Fig. 2). Targeted Sanger sequencing (forward 5'-ACAACAAATGGTGCAAT GCACA-3', reverse 5'-AAAATACAAGTCGGGCATAAAAGGG-3') was used to confirm the variant in the proband and absence of the alteration in parental samples.

\begin{tabular}{|c|c|c|c|c|c|c|c|c|}
\hline $\begin{array}{l}\text { Position (hg19/ } \\
\text { GRCh37) }\end{array}$ & Type & Gene & HGVS cDNA & HGVS protein & Zygosity & Inheritance & $\begin{array}{l}\text { SIFT/PolyPhen-2/ } \\
\text { MutationTaster2 }\end{array}$ & $\begin{array}{l}\text { ExAC/ } \\
\text { gnomAD } \\
\text { allele } \\
\text { frequency }\end{array}$ \\
\hline Chr10:131755589G >A & Missense & EBF3 & $\begin{array}{l}\text { NM_001005463.2 } \\
\text { c. } 487 C>T\end{array}$ & $\begin{array}{c}\text { NP_001005463.1 } \\
\text { p.(Arg163Trp) }\end{array}$ & Het & De novo & $\begin{array}{l}\text { Deleterious/ } \\
\text { probably } \\
\text { damaging/ } \\
\text { disease-causing }\end{array}$ & $N / R$ \\
\hline
\end{tabular}

HGVS, Human Genome Variation Society; SIFT, Sorting Intolerant from Tolerant; ExAC, Exome Aggregation Consortium; N/R, not reported. 
COLD SPRING HARBOR Molecular Case Studies
A novel de novo variant detected in EBF3

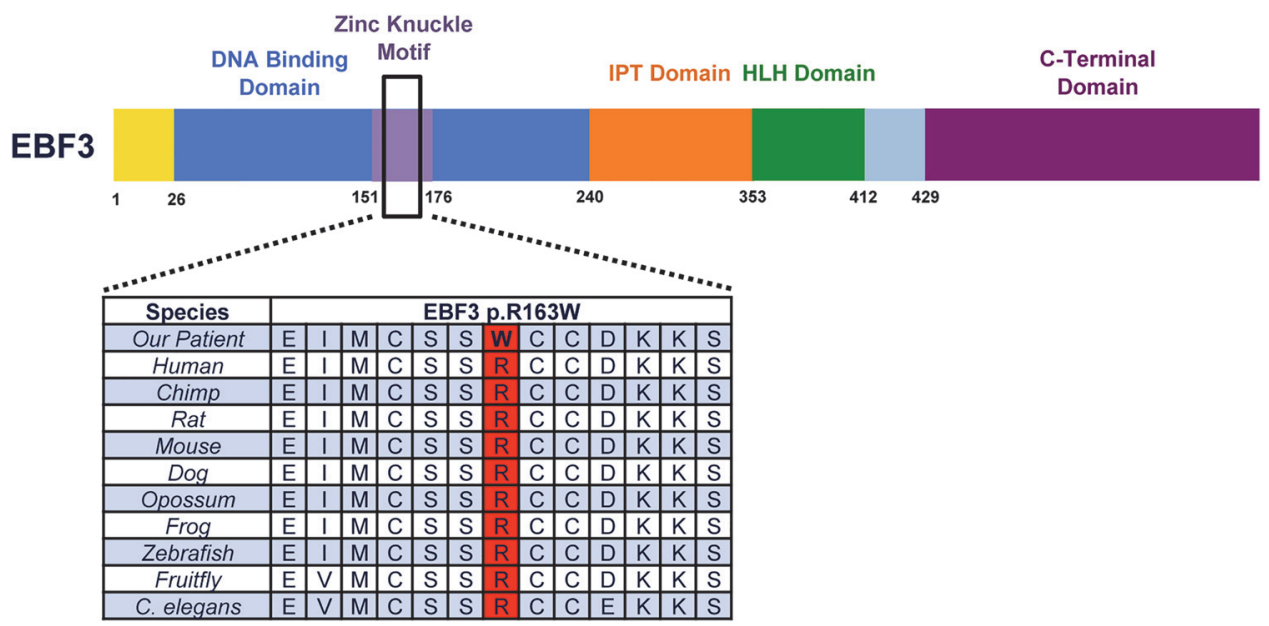

Figure 2. Schematic diagram of EBF3 (NP_001005463.1) protein structure. Numbering corresponds to amino acids.

\section{Phenotypic Analyses of Patients with EBF3 Variants}

Comparison of our patient with other recently reported cases with variants affecting the p.Arg163 residue revealed substantial phenotypic overlap (Table 2). All patients had intellectual disability, global developmental delay, speech delay, mild facial dysmorphisms, strabismus, and some urogenital anomaly, such as micropenis, cryptorchidism, urinary retention/ reflux, and/or bladder control issues (Table 2). Several structural brain abnormalities were noted in other patients on MRI, but this was not a consistent feature across all patients, including the patient described in this report. Our patient also had several urogenital anomalies including atonic bladder, distal urethral stricture, vesicoureteral reflux, bilateral hydroureter and hydronephrosis, and recurrent urinary tract infections (UTIs). Recurrent UTIs have been described in several other patients, possibly suggestive of underlying urogenital malformations, but only one other patient with a c.512G >A (p.(Gly171Asp)) variant has been described who had a diagnosis of atonic bladder (Harms et al. 2016). Our patient also had a bicornuate uterus, which has not been reported in any other patients with EBF3 intragenic variants, suggesting that this may represent an additional feature associated with this novel disorder.

\section{Molecular Modeling and Dynamics Simulations Demonstrate Loss of DNA Binding for p.(Arg163Trp)}

In this study, we used molecular modeling and physics-based atomic simulation to investigate the effects of p.(Arg163Trp) on DNA binding. Previous work in the EBF3 human paralog EBF1 has demonstrated experimentally that p.Arg163 contacts DNA, intercalating into the minor grove, and that both p.Arg163Trp and p.Arg163Ala lead to loss of DNA binding. Additionally, p.Lys239Ala interacts with DNA, but mutation to alanine had no effect on binding (Treiber et al. 2010). Thus, we generated triplicate simulation of EBF3 dimers bound to DNA for all four sequence contexts: wt, p.Lys239Ala, p.Arg163Trp, and p.Arg163Ala. Simulations revealed consistent increases in EBF3 dynamics for p.Arg163Ala and p.Arg163Trp, whereas p.Lys239Ala exhibited wt-like behavior (Fig. 3). The increased dynamics is due to loss of DNA contact by the zinc knuckle domain (see Supplemental Animation 1), which leads to greater deviations from the native conformation (Supplemental Fig. S1). To quantify the departure of the zinc knuckle from the DNA minor grove, we measured 


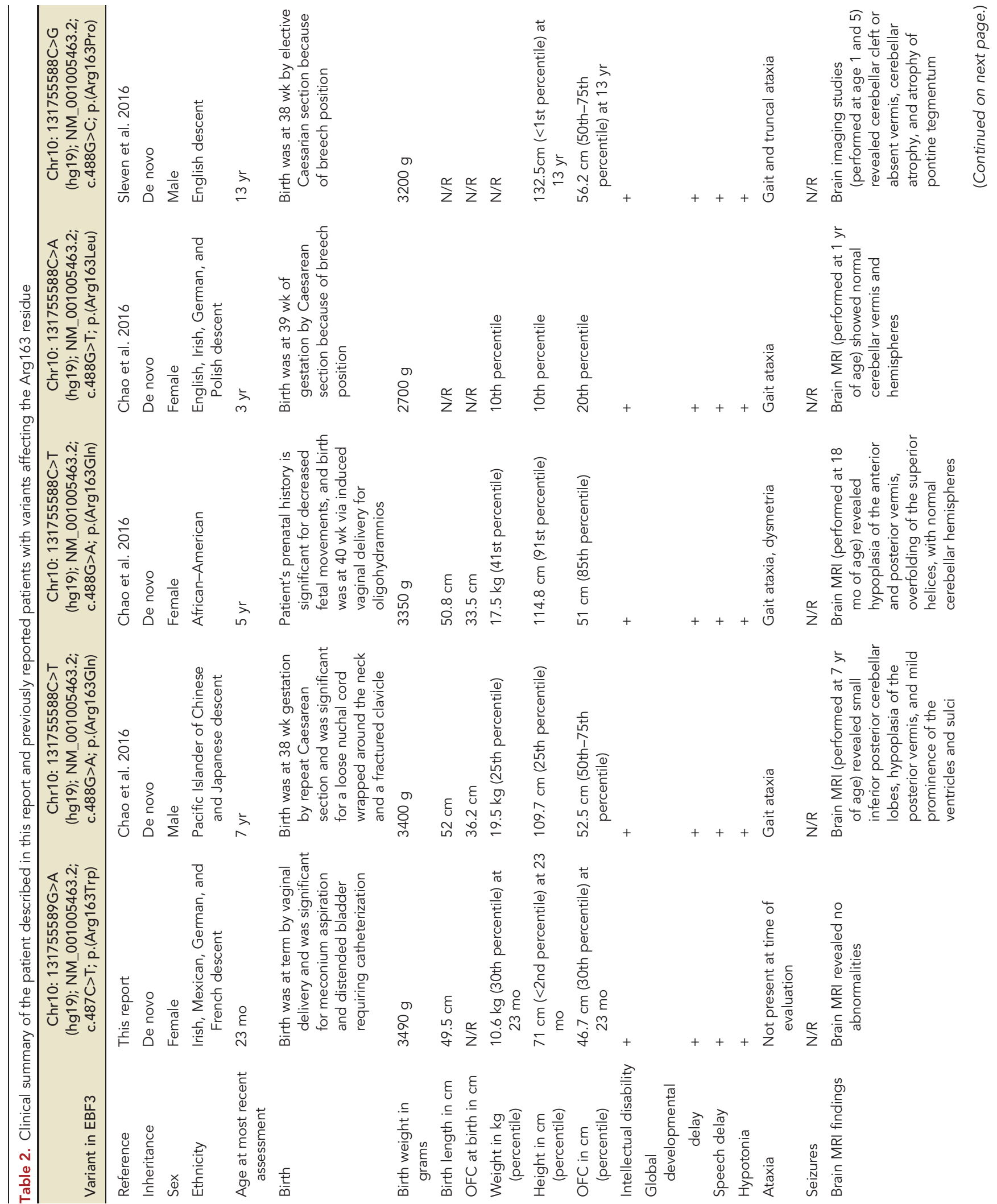




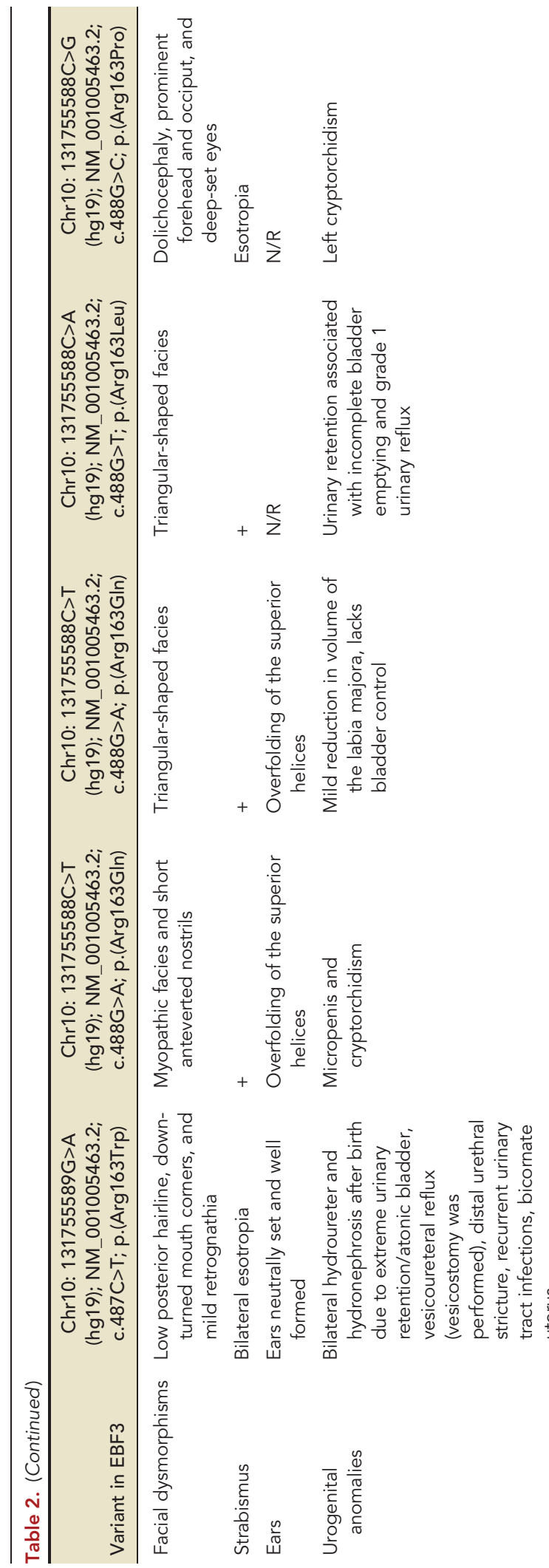

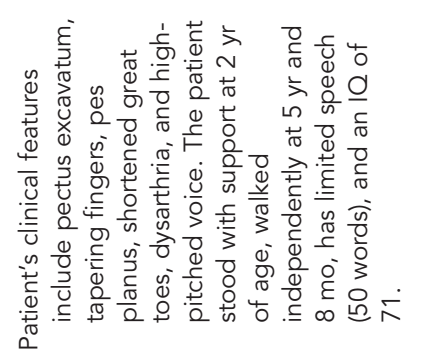
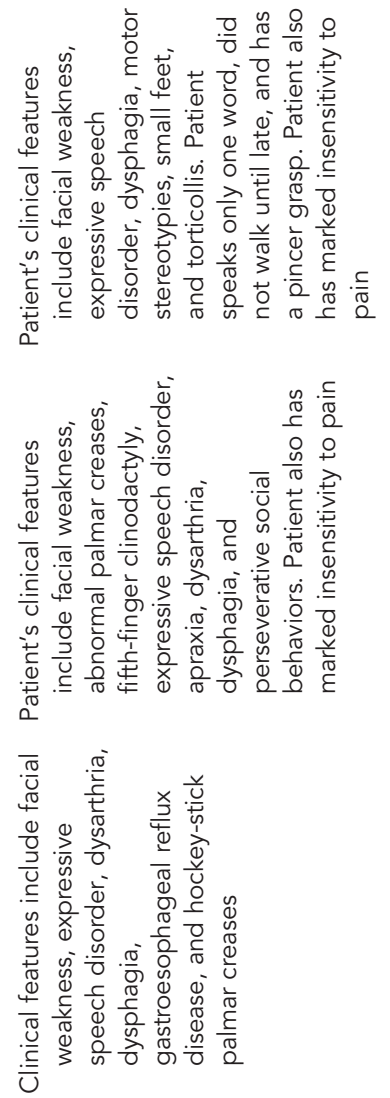
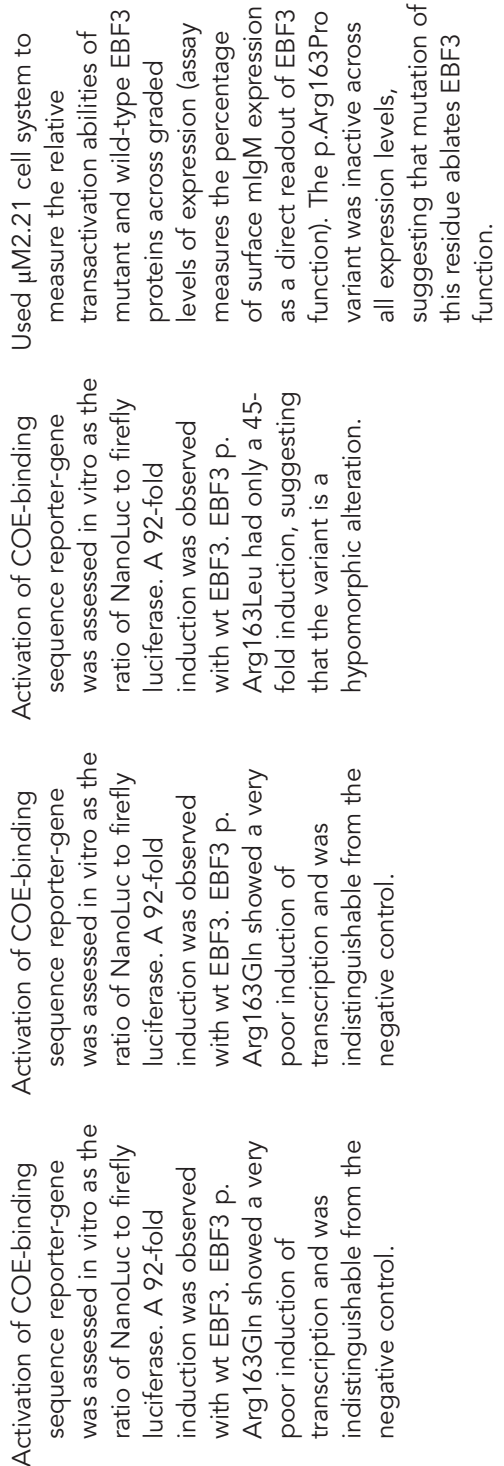

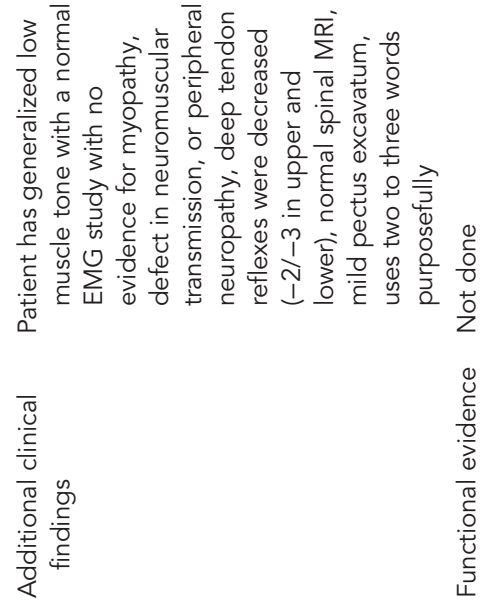

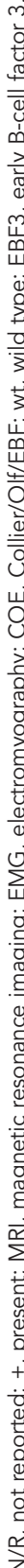



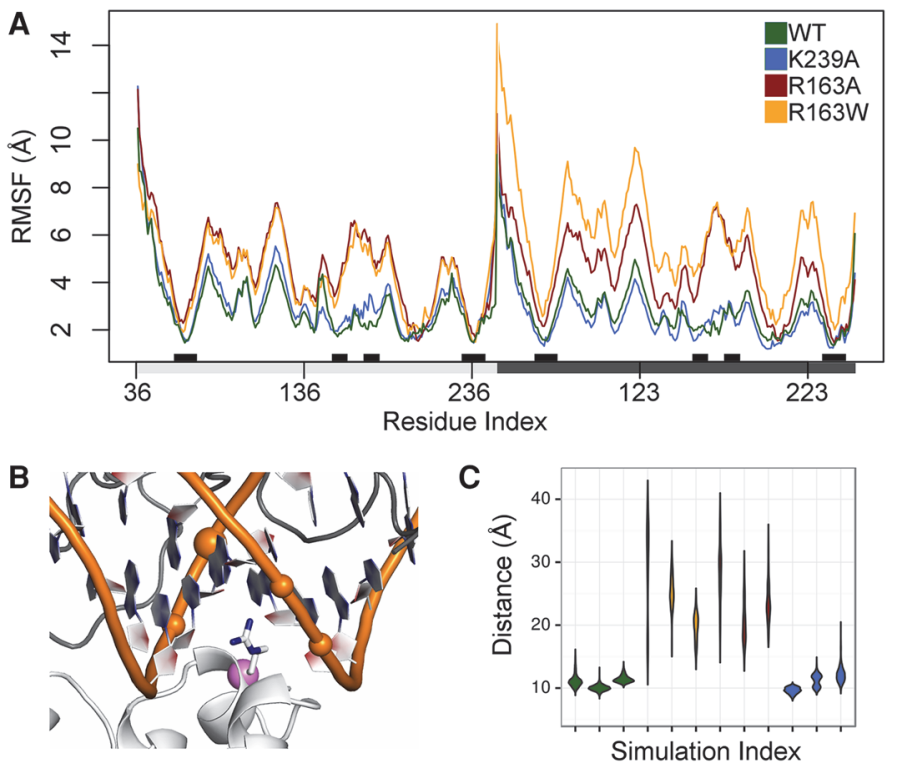

Figure 3. p.Arg163Trp induces dynamic changes throughout EBF3 that are comparable to the validated pathogenic p.Arg163Ala and distinct from control simulations. (A) We calculated the average root-mean-square deviation (RMSD) across replicates for each simulation condition (indicated by color). Proteins with alterations at residue 163 demonstrated increased mobility throughout both monomers (indicated by light and dark gray rectangles along the abscissa) with the greatest differences among the DNA-interacting regions (black rectangles) around p.Arg163. (B) To quantify the differences between conformations, we measured the distance from residue 163 (violet sphere) to nearby phosphate atoms in the DNA backbone (orange spheres). (C) We show a comparison using one of these reference distances (larger sphere in B), demonstrating that both the wild-type (wt) and p.Lys239Ala retain stable DNA interactions, whereas both p.Arg163Ala and p.Arg163Trp lose contact with DNA. Additional distance measures are presented in Supplemental Figure S2.

reference distances between the protein and DNA backbone. These distances are significantly and consistently longer for both p.Arg163 variants (see Fig. 3; Supplemental Fig. S2), whereas the wt and p.Lys239Ala remain stable. MD simulations capture both the short-scale random atomic fluctuations and the large-scale motions of the protein. We applied principal component (PC) analysis to our simulation data to identify the large-scale motions therein. We summarized these large-scale motions of EBF3, revealing that loss of contact between the zinc knuckle and DNA leads to large-scale conformations changes characterized by pivoting of EBF3 around the DNA helix axis (Supplemental Fig. S3). Thus, atomic simulations of EBF3 variants agree with biochemical experiments performed for EBF1 and indicate that p.(Arg163Trp) is likely to lead to loss of DNA affinity.

\section{DISCUSSION}

EBF3 is one of four highly related transcription factors in the COE family found in humans. EBF3 is composed of an amino-terminal DBD, an Ig-like/plexins/transcription factors (IPT) domain, a helix-loop-helix (HLH) domain, and a carboxy-terminal domain (Fig. 2; Liberg et al. 2002). The DBD coordinates a zinc ion through a histidine and three cysteine residues that form a 14-residue zinc knuckle motif that is essential for DNA binding (Hagman et al. 1995; Liberg et al. 2002). In humans, there is $97 \%$ homology at the amino acid level between EBF1 and EBF3 within the DBD, which suggests that these related proteins have similar 
DNA-binding properties (Dubois and Vincent 2001). In this report, we describe a patient with a novel p.(Arg163Trp) missense mutation that falls within a highly conserved residue in the zinc knuckle motif. Molecular modeling as well as functional confirmation in patients (see Table 2 for description of functional studies performed) with other variants affecting the $p$. Arg163 residue, strongly suggest that the variant found in our patient is pathogenic. In addition, our patient showed extensive phenotypic overlap with recently reported patients (Chao et al. 2016; Harms et al. 2016; Sleven et al. 2016). Our patient had several urogenital abnormalities, including a bicornuate uterus, which has not been described in any other patients to date and may represent an expansion of the known phenotype.

EBF3 has been less well studied than other EBF family members, but is known to be expressed in early post-mitotic neurons during development and plays a role in neurogenesis (Garel et al. 1997). In invertebrate model organisms, the EBF3 orthologs collier in Drosophila melanogaster and unc-3 (CeO/E) in Caenorhabditis elegans are expressed in mandibular and intercalary segment primordia during head specification in flies (Crozatier et al. 1996; 1999) as well as in chemosensory and developing motor neurons during axonal outgrowth in worms (Prasad et al. 1998). Studies in Xenopus revealed that EBF3 ortholog (Xebf3) is activated by XNeuroD and is expressed in primary neurons where it regulates neuronal differentiation (Pozzoli et al. 2001). At the transcriptional level in Xenopus, xebf2 and xebf3 appear to have largely overlapping patterns of expression and may have partially redundant functions (Green and Vetter 2011a). This appears to be supported by the fact that Ebf2 and Ebf3 knockout mice as well as Ebf2/3 double heterozygous knockout mice have similar phenotypes with defects in neuronal development and olfactory axon growth (Wang et al. 2004). In mice, Ebf3 is also expressed in Cajal-Retzius (CR) cells, which are important for the development of the cerebral cortex (Chiara et al. 2012). Together, Ebf2 and Ebf3 appear to regulate the migration of CR cells arising in the cortical hem during corticogenesis, and disruption of these genes leads to defects in neuronal development (Chiara et al. 2012).

Gene expression profiling comparing Arx mutant and E14.5 wild-type ventral telencephalic tissues in mice revealed that Ebf3 is one of the most differentially expressed genes in Arx mutant ganglionic eminences where it is not typically expressed (Colasante et al. 2009). Arx encodes the Aristaless-related homeobox protein, which is an essential transcription factor involved in patterning, neuronal proliferation and differentiation, and axonal outgrowth (Friocourt and Parnavelas 2010). Arx has been shown to be sufficient to repress Ebf3 expression, and defects in neuronal development in Arx mutant mice can be partially rescued through Ebf3 silencing (Colasante et al. 2009). Interestingly, pathogenic variants in $A R X$ result in a number of developmental disorders in humans including lissencephaly (LISX2; MIM\# 300215), Proud syndrome (MIM\# 300004), infantile spasms without brain malformations (EIEE1; MIM\# 308350), and syndromic (MIM\# 309510) and nonsyndromic (MIM\# 300419) mental retardation (Friocourt and Parnavelas 2010). Patients with ARX-related disorders that have CNS malformations can also present with urogenital anomalies, suggesting that the expression patterns of EBF3 and $A R X$ are both antagonistic and tightly regulated in a number of different tissues (Friocourt and Parnavelas 2010). Prior to recent reports, EBF3 had not been implicated definitively in any disorder in humans. However, patients with $10 \mathrm{q} 26$ microdeletion syndrome that includes a $3.5 \mathrm{Mb}$ minimally deleted region (SROII) involving EBF3 have several overlapping clinical features with individuals carrying EBF3 intragenic variants, including short stature, craniofacial dysmorphisms, strabismus, abnormal ears, genital anomalies, urinary tract anomalies, CNS malformations, microcephaly, and intellectual disability (Faria et al. 2016). As in ARX-related disorders, variants in EBF3 are associated with marked phenotypic and clinical heterogeneity, with some patients presenting with structural brain abnormalities and others having no evidence of CNS malformations. 
EBF3 Is Expressed in Skeletal Muscle and Is Involved in Muscle Development and Muscle-Specific Transcription

Outside of the CNS, Ebf3 shows the highest expression levels in the diaphragm, bone marrow, and skeletal muscle in developing mouse embryos (Jin et al. 2014). Adult mice express Ebf3 at the highest levels in skeletal muscle, the uterus, the eye, and the diaphragm (Jin et al. 2014). In Drosophila, collier is expressed in muscle progenitors and is required for myoblast fusion (Crozatier et al. 1999). Similarly in Xenopus, Ebf2 and Ebf3 are expressed in muscle and are required for somite organization, migration of hypaxial muscle anlagen, and the development of jaw muscle (Green and Vetter 2011b). MyoD and Myf5 appear to be direct targets of these transcription factors (Green and Vetter 2011b). MyoD can also up-regulate the expression of Ebfgenes, suggestive of a positive feedback loop between Ebf and MyoD that is necessary for differentiation of muscle cells in Xenopus (Green and Vetter 2011b). Ebf3 knockout mice die of respiratory failure before postnatal day 2 because of failure of the lung to unfold (Jin et al. 2014). This lethal phenotype is caused by a hypercontractile diaphragm with impaired $\mathrm{Ca}^{2+}$ efflux due to down-regulation of Serca1 (Atp2a1) in the absence of Ebf3 (Jin et al. 2014). EBF3 has been shown to bind to the promoter of Atp2a1 and synergizes with MYOD to induce expression of other muscle-specific target genes (Jin et al. 2014). Ebf3 is also expressed in the urogenital tract of developing mice, including regions that correspond to the detrusor muscle of the bladder and the muscle layer of the pelvic urethra (Supplemental Fig. S4) (McMahon et al. 2008; Harding et al. 2011). Given its role in muscle development and contraction, it is possible that disruption of EBF3-mediated transcription in muscle could lead to hypotonia, atonic bladder/loss of bladder control, and other phenotypes observed in patients with pathogenic EBF3 variants. Further studies will be essential to unraveling the role of EBF3 in the expression of disease in humans.

\section{METHODS}

\section{Sample Collection and WES}

Whole-exome sequencing was performed on genomic DNA extracted from all samples submitted. The exome was captured utilizing a custom reagent developed by the Mayo Clinic and Agilent Technologies, targeting 19,456 genes and 187,715 exons using 637,923 probes to capture a 54.1 Mbp total region. Sequencing was performed on an Illumina HiSeq 2500 Next-Generation sequencing instrument, using HapMap Sample NA12878 as an internal control. Paired-end 101-bp reads were aligned to a modified human reference genome (GRCh37/hg19) using Novoalign (Novocraft Technologies). Sequencing quality was evaluated using FastQC (www.bioinformatics.babraham.ac.uk/projects/fastqc/). All germline variants were jointly called through GATK Haplotype Caller and GenotypeGVCF (McKenna et al. 2010). Each variant was annotated using the BioR Toolkit (Kocher et al. 2014) and subsequently evaluated for clinical relevance. Sequencing results are shown in Table 3.

\section{Molecular Modeling and Molecular Dynamics Simulations}

Our modeling and analysis began from the UniProt sequence of EBF3 (also known as COE3), Q9H4W6, which is $97 \%$ identical to EBF1 across its DNA binding domain (Goujon et al.

\begin{tabular}{lccccccc}
\hline \multicolumn{1}{l}{ Table 3. Sequencing summary } \\
\hline $\begin{array}{l}\text { 10x } \\
\text { Coverage }\end{array}$ & $\begin{array}{c}\text { Mean } \\
\text { coverage }\end{array}$ & $\begin{array}{c}\text { Yield } \\
(\mathrm{Gb})\end{array}$ & $\begin{array}{c}>\mathrm{Q} 30 \\
(\%)\end{array}$ & $\begin{array}{c}\text { Mean } \\
\mathrm{Q}\end{array}$ & $\begin{array}{c}\text { Filtered } \\
\text { variants }\end{array}$ & $\begin{array}{c}\text { EBF3 mean } \\
\text { exon coverage }\end{array}$ & $\begin{array}{c}\text { Variant } \\
\text { coverage }\end{array}$ \\
\hline $98.63 \%$ & $140 \times$ & 15.3 & 99.92 & 38.405 & 75117 & $72 \times$ & 379 \\
\hline
\end{tabular}

Q30, quality score of 30; EBF3, early B-cell factor 3. 


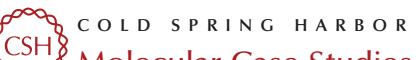
Molecular Case Studies
A novel de novo variant detected in $\mathrm{EBF} 3$
Competing Interest Statement

The authors have declared no competing interest.

\section{Referees}

Kerstin Kutsche

Peter N. Robinson

Received January 9, 2017; accepted in revised form March 6, 2017.
2010). The initial configuration of our structure was generated using homology modeling from the crystal structure of EBF1 dimer bound to DNA, 3MLP (Treiber et al. 2010), using Modeller (Martí-Renom et al. 2000) and an automated modeling approach (Zhi et al. 2014). All-atom implicit environment configurations were generated using VMD (Humphrey et al. 1996). Molecular dynamics (MD) simulations were carried out using NAMD (Phillips et al. 2005) and the CHARMM36 force field (Best et al. 2012; Hart et al. 2012). Triplicate simulations for each variant were independently energy minimized for 10,000 steps, followed by heating to $300 \mathrm{~K}$ over 600 ps via a Langevin thermostat and equilibration for $1 \mathrm{~ns}$, with a simulation time step of $1 \mathrm{fs}$ and conformations recorded every $2 \mathrm{ps}$. A further $5 \mathrm{~ns}$ of simulation trajectory was generated for analysis. Prior to analysis, all trajectories were aligned to the initial wt conformation using DNA backbone atoms. Principal component (PC) analysis was performed in Cartesian space on protein $\mathrm{C}^{\alpha}$ atoms. Analysis was carried out using custom scripts, leveraging VMD and the Bio3D R package (Grant et al. 2006). Protein structure visualization was performed in PyMOL version 1.7.6. (PyMOL 2010) and VMD v1.9.3.

\section{ADDITIONAL INFORMATION}

\section{Data Deposition and Access}

Whole-exome sequencing data is not publicly available because patient consent could not be obtained. The variant has been submitted to ClinVar (http://www.ncbi.nlm.nih.gov/ clinvar/) under accession number SCV000493129.

\section{Ethics Statement}

The proband and/or parents were consented for sample collection and subsequent analysis under a protocol approved by the institutional review board of the Mayo Clinic. Written informed consent was obtained from the proband's parents for publication and accompanying images.

\section{Acknowledgments}

We thank the patient and her family for participating in this study.

\section{Author Contributions}

P.R.B., S.S.B., M.T.Z., E.W.K., and P.N.P. designed the study. P.R.B., S.S.B., M.T.Z., M.A.C., C.K., F.P.V., Z.N., M.J.F., R.A.U., D.S., E.W.K., and P.N.P. gathered the data. P.R.B., M.T.Z., and E.W.K. analyzed the data. P.R.B., S.S.B., M.T.Z., E.W.K, and P.N.P. wrote the paper.

\section{Funding}

We thank the Mayo Clinic Center for Individualized Medicine (CIM) for supporting this research through the CIM Investigative and Functional Genomics Program.

\section{REFERENCES}
Adzhubei IA, Schmidt S, Peshkin L, Ramensky VE, Gerasimova A, Bork P, Kondrashov AS, Sunyaev SR. 2010. A method and server for predicting damaging missense mutations. Nat Methods 7: 248-249.
Best RB, Zhu X, Shim J, Lopes PEM, Mittal J, Feig M, Mackerell AD Jr. 2012. Optimization of the additive CHARMM all-atom protein force field targeting improved sampling of the backbone $\varphi, \psi$ and side-chain $\chi_{1}$ and $\chi_{2}$ dihedral angles. J Chem Theory Comput 8: 3257-3273.


Chao H-T, Davids M, Burke E, Pappas JG, Rosenfeld JA, McCarty AJ, Davis T, Wolfe L, Toro C, Tifft C, et al. 2016. A syndromic neurodevelopmental disorder caused by de novo variants in EBF3. Am J Hum Genet 100: 128-137.

Chiara F, Badaloni A, Croci L, Yeh ML, Cariboni A, Hoerder-Suabedissen A, Consalez GG, Eickholt B, Shimogori T, Parnavelas JG, et al. 2012. Early B-cell factors 2 and 3 (EBF2/3) regulate early migration of Cajal-Retzius cells from the cortical hem. Dev Biol 365: 277-289.

Colasante G, Sessa A, Crispi S, Calogero R, Mansouri A, Collombat P, Broccoli V. 2009. Arx acts as a regional key selector gene in the ventral telencephalon mainly through its transcriptional repression activity. Dev Biol 334: 59-71.

Crozatier M, Valle D, Dubois L, Ibnsouda S, Vincent A. 1996. collier, a novel regulator of Drosophila head development, is expressed in a single mitotic domain. Curr Biol 6: 707-718.

Crozatier M, Valle D, Dubois L, Ibnsouda S, Vincent A. 1999. Head versus trunk patterning in the Drosophila embryo; collier requirement for formation of the intercalary segment. Development 126: 4385-4394.

Dubois L, Vincent A. 2001. The COE-Collier/OIf1/EBF-transcription factors: structural conservation and diversity of developmental functions. Mech Dev 108: 3-12.

Faria ÁC, Rabbi-Bortolini E, Rebouças MRGO, de S Thiago Pereira ALA, Frasson MGT, Atique R, Lourenço NCV, Rosenberg C, Kobayashi GS, Passos-Bueno MR, et al. 2016. Craniosynostosis in 10q26 deletion patients: a consequence of brain underdevelopment or altered suture biology? Am J Med Genet $A$ 170A: 403-409.

Fields S, Ternyak K, Gao H, Ostraat R, Akerlund J, Hagman J. 2008. The "zinc knuckle" motif of Early B cell Factor is required for transcriptional activation of B cell-specific genes. Mol Immunol 45: 3786-3796.

Friocourt G, Parnavelas JG. 2010. Mutations in ARX result in several defects involving GABAergic neurons. Front Cell Neurosci 4: 4.

Garel S, Marín F, Mattéi MG, Vesque C, Vincent A, Charnay P. 1997. Family of Ebf/Olf-1-related genes potentially involved in neuronal differentiation and regional specification in the central nervous system. Dev Dyn 210: 191-205.

Goujon M, McWilliam H, Li W, Valentin F, Squizzato S, Paern J, Lopez R. 2010. A new bioinformatics analysis tools framework at EMBL-EBI. Nucleic Acids Res 38: W695-W699.

Grant BJ, Rodrigues APC, ElSawy KM, McCammon JA, Caves LSD. 2006. Bio3d: an R package for the comparative analysis of protein structures. Bioinformatics 22: 2695-2696.

Green YS, Vetter ML. 2011a. EBF factors drive expression of multiple classes of target genes governing neuronal development. Neural Dev 6: 19.

Green YS, Vetter ML. 2011b. EBF proteins participate in transcriptional regulation of Xenopus muscle development. Dev Biol 358: 240-250.

Hagman J, Gutch MJ, Lin H, Grosschedl R. 1995. EBF contains a novel zinc coordination motif and multiple dimerization and transcriptional activation domains. EMBO J 14: 2907-2916.

Harding SD, Armit C, Armstrong J, Brennan J, Cheng Y, Haggarty B, Houghton D, Lloyd-MacGilp S, Pi X, Roochun $Y$, et al. 2011. The GUDMAP database-an online resource for genitourinary research. Development 138: 2845-2853.

Harms FL, Girisha KM, Hardigan AA, Kortüm F, Shukla A, Alawi M, Dalal A, Brady L, Tarnopolsky M, Bird LM, et al. 2016. Mutations in EBF3 disturb transcriptional profiles and cause intellectual disability, ataxia, and facial dysmorphism. Am J Hum Genet 100: 117-127.

Hart K, Foloppe N, Baker CM, Denning EJ, Nilsson L, Mackerell AD. 2012. Optimization of the CHARMM additive force field for DNA: improved treatment of the BI/BII conformational equilibrium. $J$ Chem Theory Comput 8: 348-362.

Humphrey W, Dalke A, Schulten K. 1996. VMD: visual molecular dynamics. J Mol Graph 14: 33-38.

Jin S, Kim J, Willert T, Klein-Rodewald T, Garcia-Dominguez M, Mosqueira M, Fink R, Esposito I, Hofbauer LC, Charnay $P$, et al. 2014. Ebf factors and MyoD cooperate to regulate muscle relaxation via Atp2a1. Nat Commun 5: 3793.

Kocher J-PA, Quest DJ, Duffy P, Meiners MA, Moore RM, Rider D, Hossain A, Hart SN, Dinu V. 2014. The Biological Reference Repository (BioR): a rapid and flexible system for genomics annotation. Bioinformatics 30: 1920-1922.

Kumar P, Henikoff S, Ng PC. 2009. Predicting the effects of coding non-synonymous variants on protein function using the SIFT algorithm. Nat Protoc 4: 1073-1081.

Lek M, Karczewski KJ, Minikel EV, Samocha KE, Banks E, Fennell T, O'Donnell-Luria AH, Ware JS, Hill AJ, Cummings BB, et al. 2016. Analysis of protein-coding genetic variation in 60,706 humans. Nature 536: 285-291.

Liberg D, Sigvardsson M, Akerblad P. 2002. The EBF/Olf/Collier family of transcription factors: regulators of differentiation in cells originating from all three embryonal germ layers. Mol Cell Biol 22: 8389-8397.

Martí-Renom MA, Stuart AC, Fiser A, Sánchez R, Melo F, Sali A. 2000. Comparative protein structure modeling of genes and genomes. Annu Rev Biophys Biomol Struct 29: 291-325. 
McKenna A, Hanna M, Banks E, Sivachenko A, Cibulskis K, Kernytsky A, Garimella K, Altshuler D, Gabriel S Daly M, et al. 2010. The Genome Analysis Toolkit: a MapReduce framework for analyzing next-generation DNA sequencing data. Genome Res 20: 1297-1303.

McMahon AP, Aronow BJ, Davidson DR, Davies JA, Gaido KW, Grimmond S, Lessard JL, Little MH, Potter SS, Wilder EL, et al. 2008. GUDMAP: the genitourinary developmental molecular anatomy project. J Am Soc Nephrol 19: 667-671.

Phillips JC, Braun R, Wang W, Gumbart J, Tajkhorshid E, Villa E, Chipot C, Skeel RD, Kalé L, Schulten K. 2005. Scalable molecular dynamics with NAMD. J Comput Chem 26: 1781-1802.

Pozzoli O, Bosetti A, Croci L, Consalez GG, Vetter ML. 2001. Xebf3 is a regulator of neuronal differentiation during primary neurogenesis in Xenopus. Dev Biol 233: 495-512.

Prasad BC, Ye B, Zackhary R, Schrader K, Seydoux G, Reed RR. 1998. unc-3, a gene required for axonal guidance in Caenorhabditis elegans, encodes a member of the O/E family of transcription factors. Development 125: 1561-1568.

PyMOL 2010. The PyMOL Molecular Graphics System, Version 1.7.6. Schrödinger, LLC, New York.

Schwarz JM, Cooper DN, Schuelke M, Seelow D. 2014. MutationTaster2: mutation prediction for the deepsequencing age. Nat Methods 11: 361-362.

Sleven H, Welsh SJ, Yu J, Churchill MEA, Wright CF, Henderson A, Horvath R, Rankin J, Vogt J, Magee A, et al. 2016. De novo mutations in EBF3 cause a neurodevelopmental syndrome. Am J Hum Genet 100: 138-150.

Treiber N, Treiber T, Zocher G, Grosschedl R. 2010. Structure of an Ebf1:DNA complex reveals unusual DNA recognition and structural homology with Rel proteins. Genes Dev 24: 2270-2275.

Wang SS, Lewcock JW, Feinstein P, Mombaerts P, Reed RR. 2004. Genetic disruptions of O/E2 and O/E3 genes reveal involvement in olfactory receptor neuron projection. Development 131: 1377-1388.

Zhi H, Ning S, Li X, Li Y, Wu W, Li X. 2014. A novel reannotation strategy for dissecting DNA methylation patterns of human long intergenic non-coding RNAs in cancers. Nucleic Acids Res 42: 8258-8270. 


\section{COLD SPRING HARBOR Molecular Case Studies}

\section{Novel de novo variant in EBF3 is likely to impact DNA binding in a patient with a neurodevelopmental disorder and expanded phenotypes: patient report, in silico functional assessment, and review of published cases}

Patrick R. Blackburn, Sarah S. Barnett, Michael T. Zimmermann, et al.

Cold Spring Harb Mol Case Stud 2017, 3: a001743 originally published online March 10, 2017 Access the most recent version at doi: $10.1101 /$ mcs.a001743

Supplementary Material

References

License

Email Alerting Service
http://molecularcasestudies.cshlp.org/content/suppl/2017/03/10/mcs.a001743.D C1

This article cites 37 articles, 8 of which can be accessed free at: http://molecularcasestudies.cshlp.org/content/3/3/a001743.full.html\#ref-list-1

This article is distributed under the terms of the Creative Commons Attribution-NonCommercial License, which permits reuse and redistribution, except for commercial purposes, provided that the original author and source are credited.

Receive free email alerts when new articles cite this article - sign up in the box at the top right corner of the article or click here. 